\title{
Holding World Leaders Accountable for Climate Change- and Public Health-Commitments Through Individual Active Transportation Efforts
}

\author{
Tom Kane
}

Recently, the editors of a number of major medical journals published a joint editorial referring to the continued failure of world leaders to follow through on climate change commitments as the greatest threat to global public health, and they urge that action and not just commitments needs to be taken to make any meaningful progress in protecting health and restoring biodiversity. ${ }^{1}$ According to the World Health Organization, "[t]he enjoyment of the highest attainable standard of health is one of the fundamental rights of every human being without distinction of race, religion, political belief, economic or social condition."2 Also, according to the World Health Organization, "[h] ealth is a state of complete physical, mental, and social well-being and not merely the absence of disease or infirmity." 2

In order to ensure that world leaders stay true to their words and follow through on their commitments to protect one of our fundamental rights, world leaders must be held accountable by their constituents, individually and collectively. Constituent advocacy in the public arena and, where and when applicable, at the ballot box, is needed to achieve the commitment accountability. Governments can legislate and regulate conditions that encourage, and that are favorable to, climate change and global public health accountability at all levels of society. As one example, there is currently pending in both the US Senate and the US House of Representatives legislation that would direct the US Secretary of Transportation to carry out an active transportation investment program that would make grants available to eligible applicants to construct active transportation projects. $^{3}$

The climate change/biodiversity/public health crisis, however, is not just a government issue controlled by world leaders and governments-it is everyone's issue. Individuals can and should act, again individually and collectively, without the need for government intervention to deal with this crisis. At this stage of the crisis, individual action is not optional-it is the individuals' responsibility to take appropriate actions to protect their fundamental right to health and public health.

One way among many ways individuals can make positive contributions to the climate change/biodiversity/public health crisis is to incorporate active transportation, for example, self-propelled activities such as walking and bicycling in place of driving, ${ }^{4}$ into their daily activities of living whenever possible. Even relatively small efforts on a daily basis can add up over time, allowing individuals to reap the physical health and mental health benefits from engaging in physical activity, ${ }^{5}$ and it is never too late to start.
Constituent actions separate and apart from constituent advocacy can often pave the way for leaders and governments to follow their constituents' leads, but combining constituent actions and constituent advocacy can certainly leverage pressure on world leaders and governments to honor their commitments.

Individuals also engage in conduct, for a variety of reasons, including the conduct of business, through entities such as partnerships and corporations (which are also regulated by governments). As described in the Physical Activity Guidelines for Americans, businesses can consider access to and opportunities for active transportation in selecting new locations for their operations ${ }^{6}$; indeed, businesses should be actively looking for ways to encourage active transportation in the operation of existing operations.

Individual active transportation efforts can be a good example that can help pave the way for world leaders to be held accountable for their climate change, and public health, commitments. Taking that first step or pedaling that first bicycle wheel rotation followed by more steps and rotations is a great way for individuals to start.

\section{References}

1. Atwoli L, Baqui AH, Benfield T, et al. Call for emergency action to limit global temperature Increases, restore biodiversity, and protect health. $N$ Engl J Med. 2021;385:1134-1137. doi:10.1056/nejme 2113200

2. World Health Organization. Constitution of the World Health Organization. 2020. https://apps.who.int/gb/bd/pdf_files/BD_49th-en.pdf

3. Connecting America's Active Transportation System Act, S. 684 (2021); Connecting America's Active Transportation System Act, H.R. 2991; Surface Transportation Reauthorization Act of 2021, section 1529 et seq., S. 1931. (2021).

4. Alessio HM, Bassett DR, Bopp MJ, et al. Climate change, air pollution, and physical inactivity: Is active transportation part of the solution? Med Sci Sports Exerc. 2021;53(6):1170-1178. doi:10. 1249/MSS.0000000000002569

5. Ohrnberger J, Fichera E, Sutton M. The relationship between physical and mental health: A mediation analysis. Soc Sci Med. 2017;195: 42-49. doi:10.1016/j.socscimed.2017.11.008

6. US Department of Health and Human Services. Physical Activity Guidelines for Americans. 2nd ed. Washington, DC: US Department of Health and Human Services; 2018. 